\title{
The $\leq 10: 1$ carbohydrate to fiber ratio to identify healthy grain foods and its association with cardiometabolic risk factors in Brazil
}

\section{Abstract}

There is a pressing need for validated methods to assess healthfulness of grain foods to promote consumer awareness and policy change. We investigated how one pragmatic metric, the presence per $10 \mathrm{~g}$ of carbohydrate of at least $1 \mathrm{~g}$ of fiber ( $\leq 10: 1$-ratio), related to other constituents of grain foods as well as cardiometabolic risk factors in Brazil. Data were from the population-based study 2015 Health Survey of São Paulo, including a probabilistic sample of urban residents in São Paulo, Brazil. A total of 1,188 participants age 20 + years completed a 24-h dietary recall, and a subsample of 603 participants also had blood sample, anthropometric and blood pressure measurements collected, and answered a second 24-h recall. The National Cancer Institute method was used to estimate the usual intake of nutrients and foods. Energy and nutrient contents of grain foods meeting or not meeting the $\leq 10: 1$ ratio were evaluated using univariate linear regressions with robust variance. The association between the percent of energy (\%E) from grain foods meeting the criterion and cardiometabolic risk factors was investigated in the subsample with complete data using multivariable linear regression models. Models were adjusted for age, sex, education, income, ethnicity, smoking status, alcohol intake, physical activity, prevalent clinical diseases, and total energy intake. Mean intake of grain foods meeting the $\leq 10: 1$ ratio was $1.7 \% \mathrm{E}(95 \%$ CI $1.6 \%, 1.8 \%$ ), and $0.250 \mathrm{~g}$ servings/day. Per $50 \mathrm{~g}$ serving, foods meeting the $\leq 10: 1$ ratio criterion had lower available carbohydrate $(-3.0 \mathrm{~g} /$ serving, $\mathrm{p}=0.045)$, total sugar $(-7.4 \mathrm{~g} /$ serving, $\mathrm{p}<0.001)$, added sugar $(-7.2 \mathrm{~g} / \mathrm{serving}, \mathrm{p}<0.001)$ and saturated fatty acids $(-0.7 \mathrm{~g} /$ serving, $\mathrm{p}=0.022)$, as well as more dietary fiber $(+3.5 \mathrm{~g} /$ serving, $\mathrm{p}<0.001)$, protein $(+2.1 \mathrm{~g} / \mathrm{serving}, \mathrm{p}<0.001)$, potassium $(+100.1 \mathrm{mg} /$ serving, $\mathrm{p}=0.002)$, iron $(+0.9 \mathrm{mg} /$ serving, $\mathrm{p}=0.011)$, selenium $(+4.2 \mathrm{mcg} / \mathrm{serving}, \mathrm{p}=0.007), \mathrm{magnesium}(+38.7 \mathrm{mg} /$ serving, $\mathrm{p}<0.001)$ and zinc $(+1.1 \mathrm{mg} / \mathrm{serving}, \mathrm{p}=0.004)$. After multivariable-adjusted adjustment, each increase in $1 \% \mathrm{E}$ from grain foods meeting the $\leq 10: 1$ ratio was associated with lower levels of blood triacylglycerol $12.5 \%(95 \% \mathrm{CI}-22.4 \%,-3.8 \%)$, the triacylglycerol/HDL-c ratio $(-16.9 \% 95 \% \mathrm{CI}-30.6 \%,-4.5 \%)$, fasting insulin $(-15.3 \% 95 \% \mathrm{CI}-30.7 \%,-1.5 \%)$, and HOMA-IR (15.8\% 95\%CI $-32.8 \%,-1.0 \%)$. The $\leq 10: 1$ ratio identified grain foods with higher nutritional quality and higher intakes of these foods were associated with fewer cardiometabolic risk factors, in particular risk factors related to atherogenic dyslipidemia and insulin resistance that are influenced by carbohydrate quality. This criterion may represent a useful method for characterizing and promoting healthful grain foods.

\section{Conflict of Interest}

There is no conflict of interest. 